\title{
ESTRATÉGIAS DE ENSINO E APRENDIZAGEM PARA SURDOS NO ENSINO SUPERIOR
}

\author{
Joelaini Martins dos Reis Brasil ${ }^{1}$ \\ Taise Gomes dos Santos Cán \\ Silvia Maria de Oliveira Pavão ${ }^{3}$
}

\begin{abstract}
Resumo: O Brasil vem acompanhando uma tendência mundial propondo encaminhamentos e medidas denominadas inclusivas. No que refere ao meio universitário há uma discussão que vem ganhando espaço partindo da necessidade de adequações e inovações para a garantia de uma educação que beneficie a todos. O presente artigo constitui-se de uma pesquisa bibliográfica e desenvolveu-se a partir de uma análise integrativa, com o objetivo de compreender o fomento metodológico de permanência no Ensino Superior, em especial das estratégias de ensino utilizadas. O levantamento biográfico deu-se através da base de dados Manancial, repositório digital da UFSM, tendo como descritores os seguintes elementos: Surdez, Ensino superior, Estratégias de ensino e aprendizagem, no período de 2001 até 2019. Constatou-se que mesmo com o acesso à universidade favorecido pela legislação, os fatores da permanência, focalizados nas estratégias de ensino e aprendizagem atuais, precisam ser identificados e melhor utilizados. As estratégias foram descritas como: ação conjunta do Tradutor Intérprete de Língua de Sinais (TILS), texto didático, momento de acolhimento, acompanhamento com identificação de necessidades específicas de aprendizagem, Atendimento Educacional Especializado (AEE), reconhecimento do potencial de aprendizagem e formação continuada. Em conclusão a inclusão de surdos no Ensino Superior está na dependência do uso de estratégias de ensino e de aprendizagem combinadas e discutidas entre as partes (professor, aluno e Tradutor Intérprete de Libras).
\end{abstract}

Palavras-Chave: Surdez. Aprendizagem. Ensino Superior.

\section{TEACHING AND LEARNING STRATEGIES FOR THE DEAF IN HIGHER EDUCATION}

\begin{abstract}
Brazil has been following a global trend by proposing referrals and measures called inclusive. With regard to the university environment, there is a discussion that has been gaining ground based on the need for adjustments and innovations to guarantee an education that benefits everyone. The present article consists of a bibliographic research, with the objective of understanding the methodological promotion of permanence in Higher Education, especially of the teaching strategies used. It was found that even with access to the university favored by the legislation, the factors of permanence, focused on current teaching and learning strategies, need to be identified and better used. The strategies were described as: joint action by TILS, didactic text, moment of welcome, monitoring with the identification of specific learning needs, Specialized Educational Assistance (ESA), recognition of the learning potential and continuing education. In conclusion, the inclusion of deaf people in Higher Education is dependent on the use of combined and discussed teaching and learning strategies between the parties (teacher, student and Libras Interpreter).
\end{abstract}

Keywords: Deafness. Learning. Higher education.

\footnotetext{
${ }^{1}$ Mestrado em Educação pela Universidade Federal de Santa Maria (UFSM, 2021).

${ }^{2}$ Mestrado em Políticas Públicas e Gestão Educacional (PPPG) pela UFSM (2021).

${ }_{3}^{3}$ Docente na Universidade Federal de Santa Maria (UFSM). Doutorado em Educação pela Universidade Autônoma de Barcelona (2003).
} 


\section{ESTRATEGIAS DE ENSEÑANZA Y APRENDIZAJE PARA SORDOS EN LA EDUCACIÓN SUPERIOR}

Resumen: Brasil ha estado siguiendo una tendencia global al proponer referencias y medidas llamadas inclusivas. Con respecto al entorno universitario, existe una discusión que ha ido ganando terreno en función de la necesidad de ajustes e innovaciones para garantizar una educación que beneficie a todos. El presente artículo consiste en una investigación bibliográfica, con el objetivo de comprender la promoción metodológica de la permanencia en la Educación Superior, especialmente de las estrategias de enseñanza utilizadas. Se descubrió que incluso con el acceso a la universidad favorecido por la legislación, los factores de permanencia, centrados en las estrategias de enseñanza y aprendizaje actuales, deben identificarse y utilizarse mejor. Las estrategias se describieron como: acción conjunta de TILS, texto didáctico, momento de bienvenida, monitoreo con la identificación de necesidades específicas de aprendizaje, Asistencia Educativa Especializada (ESA), reconocimiento del potencial de aprendizaje y educación continua. En conclusión, la inclusión de personas sordas en la educación superior depende del uso de estrategias combinadas y discutidas de enseñanza y aprendizaje entre las partes (profesor, alumno e intérprete de Libras).

Palabras clave: Sordera. Aprendizaje. Educación superior.

\section{Introdução}

O crescente ingresso de estudantes com deficiência no Ensino Superior traduz o cenário de lutas que ocorreram nos anos 1980, 1990 e 2000 para a garantia do acesso à educação, um conjunto de legislações impulsionaram o contexto da educação inclusiva (BRASIL,1994; 1996; 2002; 2008; 2008a; 2014).

Tais documentações legais, balizaram o aumento da inclusão no contexto da Educação Básica e fomentaram um número considerável de matrículas de pessoas com deficiência, no Ensino Superior. Sendo assim, a universidade, parte integrante da implementação de políticas públicas, não é a única responsável por este processo, o aumento de matrículas não reflete também as desistências ou reprovações em cursos de Ensino Superior, pois sabe-se que o fato do aluno estar na sala de aula não significa que o mesmo esteja incluído é necessária uma estrutura organizada para receber esses alunos na instituição de ensino. Em especial no que tange à organização metodológica, cujas estratégias pedagógicas utilizadas, podem ser determinantes para o engajamento da própria pessoa com deficiência, bem como de toda a comunidade acadêmica, além de outros fatores, tais como de infraestrutura e de apoio financeiro às ações requeridas com as novas práticas.

A legislação na área da inclusão educacional, teve importante impulso em nível mundial com a promulgação da Declaração de Jomtien ou também chamada de Declaração Mundial de Educação para Todos (UNESCO, 1990), com a Declaração de Salamanca 
(BRASIL, 1994) e, no Brasil, com a lei de Diretrizes e Bases da Educação NacionalLDBen (BRASIL, 1996), que determinam um arsenal de medidas para a inclusão de pessoas com deficiência e, estão sendo gradativamente sendo absorvidas pela sociedade. No interior das instituições educacionais, suscitaram a oportunidade de acesso e a necessidade de mudanças e redefinições contextuais, metodológicas e estruturais.

Práticas instituídas até então, começaram a ser questionadas, ganhando respaldo pelo aviso Circular no 277/MEC/GM/1996 (BRASIL, 1996), que orienta acerca de medidas de acessibilidade para os alunos com deficiência. De acordo com esse documento, os primeiros ajustes foram realizados nos processos de ingresso no Ensino Superior, com modificações tanto no edital de seleção como no momento de aplicação e correção das provas.

Em vista dessas orientações, foram exigidas das comissões de seleção, mudanças quanto aos critérios de avaliação, organização de salas e recursos adaptados necessários para que o candidato pudesse realizar a prova, como, também, avaliar as especificidades inerentes a cada deficiência no momento da correção do processo avaliativo (BRASIL, 1996).

Neste sentido, se observou que as condições de acesso foram garantidas, trazendo mudanças significativas em todos os âmbitos da sociedade, pessoas com deficiência começaram a ganhar espaço como cidadãos, como consequência de suas lutas encontrarem eco perante o poder público. Entretanto, mesmo que o acesso ao Ensino Superior estivesse garantido, surgiram as obrigações no contexto da universidade, uma delas está relacionada a permanência desses alunos em par de igualdade na construção de aprendizagem com os demais.

A Portaria no 1.679/1999 (BRASIL, 1999, art.1º), “dispõe sobre requisitos de acessibilidade de pessoas com deficiências, para instruir os processos de autorização e de reconhecimento de cursos, e o credenciamento de instituições”. Ato contínuo, define uma série de condições em termos da infraestrutura, materiais pedagógicos, "softwares específicos, entre outros, quanto aos recursos humanos a presença de intérprete de língua de sinais/língua portuguesa (BRASIL, 1999, art 2º).

Um aspecto que merece destaque na Portaria 1.679/1999 (BRASIL, 1999, art 2º) é a atenção para a pessoa surda, enfatizando a presença do intérprete de libras em sala de aula, mesmo que a Lei de reconhecimento da Libras, viesse a ser oficializada somente três anos após, em 2002 pela Lei 10.426 (BRASIL, 2002). 
No que se refere a educação de surdos no contexto brasileiro, existe discussão do cenário de lutas da comunidade surda. Isso é apontado por Strobel; Perlin (2006) como uma mudança paradigmática, reconhecendo o sujeito surdo a partir de sua diferença linguística. Os Estudos Culturais partilharam dessa perspectiva, deslocando a questão da surdez do campo da deficiência, permitindo assim um novo olhar não como incapacidade, ou deficiência, mas ao enxergar o surdo a partir de sua identidade e cultura.

Tal entendimento é corroborado por pesquisadores na área de educação de surdos, que propõe olhar a surdez de outro lugar que não o da deficiência, mas o da diferença cultural em razão da diferença linguística (GÓES, 1999; PERLIN; STROBEL, 2006; CORCINE, 2007; WITCHS; LOPES; COELHO, 2019).

Esta mudança de perspectiva que toma o comportamento linguístico do surdo, aliado ao respeito às diferenças propiciaram condições para sua participação ativa em diferentes espaços sociais, entre eles a universidade. Face ao período relativamente extenso dessas discussões acerca do ingresso das pessoas com deficiência - em especial dos surdos- na Educação Superior, já perfazem duas décadas, contadas a partir de 1994, pela Declaração de Salamanca, que pode ser considerada um marco impulsionador da educação inclusiva (BRASIL, 1994), soma-se a análise do número de pessoas surdas que concluem os cursos em nível superior.

Os dados do Instituto Nacional de Estudos e Pesquisas Educacionais Anísio Teixeira-INEP apontam que entre os anos de 2010 a 2016, ingressaram um total de 2.474 alunos surdos nas Instituições de Ensino Superior-IES públicas do Brasil, totalizando no mesmo período apenas 40 alunos surdos diplomados (BRASIL, 2017); com tais considerações se delineou o presente estudo. $\mathrm{O}$ mote da investigação problematizou o período em que as pessoas permanecem nas Instituição de Ensino Superior, do ingresso à conclusão, buscando compreender os processos de permanência, cujas estratégias de ensino e aprendizagem ganham evidência.

O estudo possui relevância na medida que considera a emergência de pesquisas, acerca das práticas de permanência de inclusão, em especial das estratégias de ensino e aprendizagem, neste sentido, é que o objetivo do estudo consiste em: entender o processo de permanência das pessoas surdas a partir das estratégias de ensino e aprendizagem utilizadas no contexto da IES em destaque, e que considerem as diferenças linguísticas. 


\section{Método}

Com característica qualitativa, o estudo desenvolveu uma pesquisa bibliográfica (GIL, 2008) e o método de análise da revisão integrativa (MENDES; SILVEIRA; GALVÃO, 2008; SOUZA; SILVA; CARVALHO, 2010). A revisão integrativa orienta para a construção analítica da literatura, com uma síntese e generalizações sobre o fenômeno investigado. Além disso, a revisão integrativa permite uma ampla gama de fontes de pesquisa, não oferecendo qualquer tipo de discriminação quanto ao tipo de metodologias utilizadas, período em que a investigação ocorreu, quantitativos ou outros.

Mendes, Silveira e Galvão (2008) e Souza, Silva e Carvalho (2010) orientam que a realização da revisão integrativa integre seis distintas etapas, quais sejam: 1) definição do tema e problema; 2) apresentação dos critérios de inclusão e exclusão das fontes de pesquisa; 3) indicação das informações que serão extraídas; 4) avaliação dos estudos; 5) interpretação e análise; e 6) revisão e síntese do conhecimento construído.

Nesse sentido, o tema e a delineação do problema, se definiu considerando o decurso de tempo das políticas de inclusão e os dados do Censo da Educação Superior acerca do ingresso e conclusão de surdos, cuja defasagem extrapola o percentual de $100 \%$ no período de cinco anos analisado.

A seleção das fontes de investigação para a construção de um corpus, ocorreu em duas etapas: a primeira etapa considerou, por meio de amostra intencional, apoiada no estudo de Lima (2018, p. 54), que identificou uma IES pública com um número significativo de alunos surdos e a existências e efetividades de políticas de inclusão por mais de dez anos, sendo assim uma instituição recomendada para a análise que se destina a presente investigação, pelas peculiaridades na área da surdez: "considerada uma das pioneiras no Brasil, em realizar o vestibular em vídeo gravado em Libras no ano de 2010, pela implementação de normatizações [...]”.

Na segunda etapa de seleção das fontes, se realizou um levantamento bibliográfico nas bases de dados da mesma IES. Especificamente, no Manancial-Repositório Digital da IES, que reúne a produção científica, técnica, artística e acadêmica da universidade em um único ambiente de livre acesso (UNIVERSIDADE FEDERAL DE SANTA MARIA, 2020).

Foram incluídos nas buscas, apenas dissertações e teses do Manancial, no período de 2001 a 2019. A pesquisa utilizou esse extenso período para delimitar o campo da busca, tendo por referência, os principais documentos na área da educação especial que foram 
publicados nesse período, tais como: documento sobre a educação para todos (BRASIL, 2000) Diretrizes Nacionais para a Educação Especial na Educação Básica (BRASIL, 2001) e a institucionalização da Política Nacional de Educação Especial na Perspectiva da Educação Inclusiva (BRASIL, 2008).

Os descritores para esta busca foram: surdez, Ensino Superior; Estratégias de aprendizagem; Estratégias de Ensino. As palavras deveriam estar associadas e poderiam estar dispostas entre o título, resumo e/ou palavras-chave. Na busca, foram encontrados 190 dissertações de mestrado e 54 teses, nessa etapa de seleção foram lidos: título, resumo e palavras-chave. Foram selecionadas apenas seis dissertações, por atenderem aos critérios de inclusão da amostra: extração dos aspectos correlacionados as estratégias (Quadro 1).

Na sequência foi efetivada a leitura na íntegra das seis dissertações. Dessa leitura, os dados extraídos, buscaram atender ao objetivo, de forma que as estratégias de ensino e aprendizagem utilizadas por surdos na Educação Superior, se consolidou como a principal informação (Quadro 1). Os dados analisados de forma qualitativa, permitiram a apresentação de uma síntese pontual quanto as estratégias de ensino com surdos, que possam melhor beneficiar os surdos a concluir os cursos em nível superior, obtendo a diplomação.

Quadro 1: Fontes de investigação.

\begin{tabular}{|c|c|c|}
\hline Título da dissertação, autor e ano & $\begin{array}{l}\text { Extração dos } \\
\text { aspectos } \\
\text { correlacionados } \\
\text { as estratégias }\end{array}$ & Objetivo do estudo \\
\hline $\begin{array}{l}\text { Ingresso, acesso e permanência dos alunos } \\
\text { com necessidades educacionais especiais na } \\
\text { Universidade Federal de Santa Maria - } \\
\text { UFSM - RS } \\
\text { Autora: Cleonice Machado de Pellegrine } \\
\text { Ano:2006 }\end{array}$ & Permanência & $\begin{array}{l}\text { Investigar o Ingresso, Acesso e Permanência } \\
\text { dos Alunos com Necessidades Educacionais } \\
\text { Especiais na Universidade Federal de Santa } \\
\text { Maria - UFSM - RS. }\end{array}$ \\
\hline $\begin{array}{l}\text { Acesso e permanência no ensino } \\
\text { superior: estratégias de governamento da } \\
\text { conduta de alunos surdos incluídos } \\
\text { Autora: Ravele Bueno Goularte } \\
\text { Ano: } 2014\end{array}$ & $\begin{array}{l}\text { Permanência } \\
\text { Estratégia de } \\
\text { governamento }\end{array}$ & $\begin{array}{l}\text { Analisar como vêm se dando os processos de } \\
\text { governamento dos alunos surdos da UFSM. }\end{array}$ \\
\hline $\begin{array}{l}\text { O currículo e a inclusão na educação } \\
\text { superior: ações de permanência nos cursos de } \\
\text { graduação da UFSM } \\
\text { Autora: Eliane Sperandei Lavarda } \\
\text { Ano:2014 }\end{array}$ & $\begin{array}{l}\text { Ações de } \\
\text { Permanência }\end{array}$ & $\begin{array}{l}\text { Analisar as Ações de Permanência necessárias } \\
\text { ou não em relação ao currículo dos cursos de } \\
\text { graduação para o processo de inclusão de } \\
\text { alunos com NEE na Educação Superior. }\end{array}$ \\
\hline $\begin{array}{l}\text { Estratégias de ensino para acadêmicos surdos } \\
\text { na educação superior } \\
\text { Autora Juliana Corrêa de Lima } \\
\text { Ano: } 2018\end{array}$ & $\begin{array}{l}\text { Estratégias de } \\
\text { ensino }\end{array}$ & $\begin{array}{l}\text { Entender de que forma as estratégias de ensino } \\
\text { utilizadas pelos professores contribuem para a } \\
\text { aprendizagem de acadêmicos surdos nos } \\
\text { Cursos de Graduação da Universidade Federal } \\
\text { de Santa Maria (UFSM). }\end{array}$ \\
\hline $\begin{array}{l}\text { Trajetórias escolares de estudantes surdos e } \\
\text { seus efeitos nos processos inclusivos no } \\
\text { ensino superior }\end{array}$ & $\begin{array}{l}\text { Experiências } \\
\text { escolares }\end{array}$ & $\begin{array}{l}\text { Compreender quais os efeitos das trajetórias } \\
\text { escolares de estudantes surdos no contexto do } \\
\text { Ensino Superior, no caso deste estudo, na }\end{array}$ \\
\hline
\end{tabular}




\begin{tabular}{|l|l|l|}
\hline $\begin{array}{l}\text { Autora: Laisa de Castro Almeida } \\
\text { Ano:2018 }\end{array}$ & $\begin{array}{l}\text { Universidade Federal de Santa Maria. Para } \\
\text { isso, foi necessário identificar quais eram as } \\
\text { experiências escolares dos acadêmicos surdos, } \\
\text { desde a educação básica até a situação atual. }\end{array}$ \\
\hline $\begin{array}{l}\text { Vivência acadêmica de estudantes surdos na } \\
\text { UFSM: ingresso, adaptação, permanência e } \\
\text { conclusão }\end{array}$ & $\begin{array}{l}\text { Vivências dos } \\
\text { surdos } \\
\text { Autora: Mariléia Lúcia Stolz } \\
\text { Ano:2019 }\end{array}$ & $\begin{array}{l}\text { Compreender a vivência de estudantes surdos } \\
\text { na Universidade Federal de Santa Maria. }\end{array}$ \\
\hline
\end{tabular}

Fonte: Manancial - Repositório Digital da UFSM.

A análise desses dados, considerou a extração dos aspectos correlacionados ao tema e objetivo dos estudos selecionados, realizados a partir disso uma discussão qualitativa. As palavras que mais se evidenciaram nessa análise foram: permanência, ação e experiências. Tais palavras, submetidas a apreciação de conceitos e significados, permitiram inferir acerca do período formativo dos estudantes, que é considerado o período de permanência na instituição. As questões sobre esse período colocam em jogo, as experiências pedagógicas, o que é realizado para obter melhor desempenho e aprendizagem. Nesse sentido, as dissertações mostram ser documentos legítimos para a análise das estratégias que são utilizadas com estudantes surdos.

\section{Percurso Formativo do Estudante Surdo na Educação Superior}

Para compreender e discutir a questão do aluno surdo no contexto do Ensino Superior, é necessário fazer uma retrospectiva da história da educação de surdos e, de como os paradigmas educacionais vigentes definiram o olhar para esse sujeito. A partir de fatos, lutas, conquistas que marcaram historicamente o movimento surdo, chegou-se, ao momento atual, com uma demanda de acadêmicos surdos crescente nas IES.

A educação de Surdos no Brasil é perpassada por várias correntes, as quais remontam um passado de conquistas e lutas. No Brasil em 1857 é criado com o apoio do Imperador Dom Pedro II o Imperial Instituto de surdos mudos que adotava a filosofia e a disseminação da Língua de Sinais com influência francesa. Edward Hernest Huet (18221882) foi um educador que trouxe da França a institucionalização da Língua de Sinais como ferramenta de ensino (PERLIN; STROBEL, 2006).

De acordo com Stumpf (2006), em 1880 a educação de surdos sofre um ataque, pois é instaurado o oralismo, perspectiva de ensino que primava o não uso da Língua de Sinais, fato este que resultou em atrasos no desenvolvimento de tais sujeitos, e o principal objetivo da escola passou a ser ensinar crianças surdas aprender a falar, recebendo treinamento oral. Nesta perspectiva a sistematização do ensino foi deixada de lado, gerando uma queda significativa no nível de escolarização dos alunos com surdez. 
A partir dos anos noventa com a publicação da Lei de Diretrizes e Bases da Educação-LDBen (BRASIL, 1996), há então um enfoque aliado ao paradigma da inclusão, o qual tem como objetivo a promoção de uma educação para todos. Deste modo, o surdo é incluído no ensino regular sem que a discussão do método de ensino fosse reconsiderada e a visão clínica e oralista desconsiderada. Em 24 de abril 2002, após muitas mobilizações da comunidade surda, a Lei $n^{\circ} 10.436$ é sancionada, reconhecendo a Língua Brasileira de Sinais como meio legal de comunicação e expressão. Sendo assim o Bilinguismo, é concretizado como um movimento contrário a visão terapêutica da surdez, incorporando a Língua de Sinais como meio natural de aprendizagem e comunicação.

Nesta perspectiva, os surdos enquanto comunidade, detém uma língua e cultura própria. A aprendizagem da língua oral não deixa de ser importante para o surdo, no entanto, o mesmo tem a Libras como sua primeira língua e essa deve ser respeitada e valorizada nos contextos educacionais. A educação de surdos a partir do entendimento que a pessoa com surdez tem uma língua e que está deve ser vista sob a ótica da diferença e não da deficiência, alia aos estudos culturais o entendimento de quem é este sujeito. No que diz respeito à concepção de surdez, os Estudos Surdos distanciam-se dessa perspectiva conceituada como deficiência e entende a pessoa surda a partir da lógica da diferença Linguística. Nesta direção, Corcine (2007, p. 26) destaca a surdez "como um marcador cultural, que se desfaz da visão clínica, com a ênfase colocada no caráter cultural da surdez".

Este redimensionamento propiciou o fortalecimento e o protagonismo de surdos em cursos de graduação, de acordo com o último censo da educação superior de 2017 realizado pelo Instituto Nacional de Estudos e Pesquisas Educacionais Anísio Teixeira (INEP), os alunos surdos representaram, como mencionado um total de 2.474 matrículas em cursos de graduação.

Entretanto, quando chegam a universidade tem assegurado o respeito a sua Língua, porém entram em contato com um universo, onde a Língua Portuguesa é utilizada para a maioria dos caminhos de aprendizagem (PELLEGRINE, 2006; GOULARTE 2014; LAVARDA, 2014; LIMA 2018; ALMEIDA, 2018; STOLZ, 2019).

Em relação ao acesso de acadêmicos surdos no Ensino Superior a Lima (2018) destaca a Universidade Federal de Santa Maria-RS, como uma instituição pioneira em ofertar o vestibular em Libras para candidatos surdos assegurando a presença do Tradutor Intérprete de Libras-TILS no momento da prova em vídeo na língua de sinais, também 
pioneira, na proposições das Ações Afirmativas, por meio de resoluções internas que foram implantadas na referida IFE, a qual reserva 5\% das vagas de ingresso para esse público antes mesmo da Lei Federal de Cotas, $\mathrm{n}^{\circ}$ 12.711/2012, ser aprovada e regulamentada pelo Decreto $\mathrm{n}^{\circ} 7.824 / 2012$, que dispõe sobre o ingresso em Universidades Federais e Instituições Federais de ensino técnico de nível médio (BRASIL, 2012).

As cotas são divididas em relação à renda, escolarização pública, autodeclarados pretos, pardos e indígenas, não sendo obrigatória a destinação de vagas às pessoas com deficiência. A IFE opta pela inclusão e isto abre a possibilidade para a diversidade e o respeito às diferenças individuais, e esta preocupação com a acessibilidade fez com que a procura e o número de surdos tenham aumentado consideravelmente. Uecker; Bueno; Fiorin (2018, p. 144) entendem que: é a universidade um espaço para muitas aprendizagens e por isso esse processo de aprender precisa ser discutido, pois o aprender ocorre com as demais pessoas, "no perceber potencialidades e atitudes que vêm ao encontro das carências interpessoais. O conhecimento produzido a partir destas relações é que torna o mundo e as pessoas mais humanas e capazes de viver em harmonia".

O estudo de Stolz (2019) mostrou a vivência acadêmica dos estudantes surdos na UFSM, buscando compreender esse processo a partir da permanência e conclusão da graduação, analisou e identificou quais domínios do processo de vivência acadêmica irão contribuir para a experiência na universidade. Os domínios elencados foram: pessoal, relacionamento interpessoal, carreira, estudo e institucional.

A autora entendeu que compreender a vivência desses estudantes é possível entrando em contato com os mesmos, pois somente eles podem externar o que sentem e afirmar as suas percepções acerca da educação superior, pois estudos dessa natureza possibilitam que instituições acadêmicas interajam melhor com o ensino de surdos nesses espaços, proporcionando aos docentes as orientações necessárias para que possam contribuir com qualidade nos processos de ensino e aprendizagem da comunidade surda.

Conforme Stolz et al. (2019, p. 171-172) no período de 1982 a 2002, apenas três alunos ingressaram nessa IFE, pois as políticas públicas não garantiam a acessibilidade e o ingresso no Ensino Superior. Foi somente a partir do ano de 2010, quando houve a oferta do vestibular em Libras, que o quantitativo significativo de matrículas aumentou. Nesse período, até o ano de 2018 foram matriculados 52 alunos. Entretanto, de 2012 a 2018, 27 alunos surdos desistiram dos cursos. E, em relação ao número de alunos diplomados nessa IFE, considerando o período de 1985 a 2016 foram apenas seis concluintes dos cursos. 
Segundo Uecker; Bueno; Fiorin (2018) que mesmo no Ensino Superior, em que os alunos são jovens e adultos, o aprendizado não ocorre facilmente, pois os componentes curriculares podem ser mais complexos que os esperados, entre outras condições encontradas no ambiente universitário.

No que tange ao aspecto curricular, Lavarda (2014) discutiu sobre o currículo e a inclusão na educação superior, contemplando as ações de permanência nos cursos de graduação da UFSM, visto que o currículo foi concebido nesse trabalho como o processo educacional completo do aluno, desde o momento do ingresso. Ao entrevistar coordenadores de curso, constatou que os coordenadores são informados com antecedência a respeito do ingresso dos alunos com deficiência, tendo a possibilidade de planejar propostas de educação inclusiva tanto de caráter administrativo quanto pedagógico, realizando o repasse da informação aos demais professores que atuarão no início dos cursos. Inclusive, a coordenação tem a possibilidade de solicitar o auxílio da família para realizar as adaptações que poderão facilitar as ações de permanência.

Em contrapartida, nesse estudo também houveram casos em que os coordenadores não foram comunicados e sim, ficaram sabendo pelo próprio aluno ou até mesmo na metade do semestre, o que prejudicou o planejamento das ações de permanência e acessibilidade desses alunos.

No que tange a aceitação dos professores, os mesmos demonstram um misto de reações: aceitação e insegurança. Aceitação pelo fato de acreditar na importância de inclusão no processo educativo e insegurança por receber um aluno com deficiência e alegar não receber uma formação específica para atender essa demanda, o que leva o docente a repensar suas práticas pedagógicas e adaptar suas aulas para o universo daquele aluno. A falta de conhecimento acerca da inserção do aluno com deficiência dificulta a compreensão das suas necessidades individuais e limita a qualidades dos processos de ensino e aprendizagem. O déficit na comunicação entre docentes, acerca do ingresso de alunos com deficiência nas instituições, pode prejudicar o desempenho acadêmico. (LAVARDA, 2014).

Conforme Ferreira e Cezar (2018, p. 329), "os surdos que ingressam hoje no Ensino Superior não vivenciaram uma inclusão de fato, isso se deve provavelmente, pelo histórico educacional, quer dizer, que tipo de escola fizeram o Ensino Básico que antecedeu o ingresso na universidade, qual o conhecimento da Língua Brasileira de Sinais, ou mesmo da língua portuguesa, são questões que impactam no desempenho acadêmico. 
Nessa direção, Almeida (2018) buscou compreender através de narrativas os efeitos das trajetórias escolares de estudantes surdos da UFSM, a partir da identificação das suas respectivas experiências escolares desde a educação básica até o ingresso no Ensino Superior, no entendimento dos efeitos produzidos pelos discursos que permeiam as narrativas dos estudantes e da problematização da constituição do estudante surdo no contexto universitário.

Ficou evidente que as experiências escolares deixaram marcas na vida dos acadêmicos surdos e produzem efeitos no contexto universitário, como por exemplo: a relação de assistencialismo, os processos de oralização e o não reconhecimento da Libras que constitui a base linguística desses alunos e a exclusão desses alunos no âmbito da educação superior, considerando que há evidências de maior participação dos alunos surdos nos espaços específicos da educação de surdos.

A partir de pressupostos inclusivos, Pellegrini (2006) que investigou o ingresso, acesso e permanência dos alunos com necessidades educacionais especiais nos cursos de graduação no âmbito da UFSM, constatou os fatores que dificultaram a inclusão desses alunos. Um deles pautou-se na importância de reconhecê-los, considerando a escassez de dados quantitativos e qualitativos desse público em pesquisas e na instituição, pois cada aluno é provido de características peculiares carregadas de sentido, significado, vivências, expectativas e ansiedade que irão repercutir durante a inserção acadêmica. Se evidencia a importância da conscientização para eliminar as barreiras arquitetônicas, fatores ambientais e barreiras atitudinais, a fim de que os alunos sejam reconhecidos e tenham condições dignas de permanência institucional, permeados pelo respeito à diversidade e pelo princípio da educação para todos.

De acordo com Daroque e Padilha (2012), no que se refere o ao ingresso de alunos surdos nos cursos de graduação, seus anos de escolarização prévia não criaram (e ainda não criam) condições apropriadas de reconhecimento da língua portuguesa como uma língua de reflexão, apropriação e desenvolvimento da leitura e escrita, restringindo o acesso a conhecimentos que, no Brasil, estão maciçamente registrados nesse idioma.

Talvez esse seja o ponto de reflexão sobre o porquê das 27 desistências nesse caminho ao longo do processo de inclusão na IFE, estar num curso de graduação onde a língua majoritária é o português, essa questão pode gerar mais dificuldades de aprendizagem.

Para Santana (2016), o letramento acadêmico de surdos ainda é fragmentado formado por poucos hábitos de leitura e escrita. O letramento acadêmico que envolve os 
gêneros secundários (trabalhos de conclusão de curso, relatórios, provas, livros didáticos) são mais complexos para os surdos. Principalmente porque os acadêmicos surdos de hoje foram os surdos educados a partir de uma perspectiva oralista, o que não garantia o acesso dos surdos a cultura escrita nem a práticas significativas com a linguagem escrita. Ou seja, os surdos que adentram ao Ensino Superior levam resquícios desta educação limitadora que os condicionou a ter sérios problemas com a língua escrita.

Bisol et al (2010) apontam a realidade de estudantes surdos no Ensino Superior em contextos de inclusão, no que tange a comunicação em sala de aula e o envolvimento com a aprendizagem, mostram que as ações são similares a de seus colegas ouvintes, mas eles se sentem menos integrados à vida universitária. Isso pode ser motivado pela falta de adaptações nos materiais pedagógicos que favoreçam os alunos surdos. Importante destacar que os acadêmicos surdos enfrentam problemas quanto a recepção das informações (tempo entre o que é falado e a tradução); quebra de contato visual enquanto o professor escreve no quadro, caminha pela sala ou lê um documento, o que impede a leitura labial; perda de informação quando é preciso escolher entre olhar para o intérprete ou observar o professor enquanto este manuseia um objeto em laboratório ou trabalha com imagens.

A inclusão do surdo, vai para além da presença de intérprete da Língua de Sinais, ou a garantia do respeito à Língua de Sinais. Há pressupostos que podem garantir ou não uma efetiva inclusão de tais acadêmicos, esses pressupostos passam pelas estratégias de permanência.

\section{Estratégias para a Permanência de Estudantes Surdos no Contexto do Ensino Superior}

A metodologia de ensino para acadêmicos surdos, corresponde um desafio que abrange conteúdos singulares, é necessária uma sistematização pedagógica, pensando no conhecimento prévio dos alunos, selecionando os conteúdos que venha a contribuir para o desenvolvimento sempre respeitando suas diferenças individuais (LIMA, 2018).

De acordo com Lacerda et al. (2014, p. 2) os surdos "se encontram imersos no mundo visual e apreendem, a partir dele, a maior parte das informações para a construção de seu conhecimento. Para os surdos os conceitos são organizados em língua de sinais [...]". Neste processo a língua de sinais, configura-se como o meio de acesso à informação pelos surdos, para que esta interlocução aconteça é necessário e previsto na legislação a atuação de profissionais intérpretes de Libras no contexto da sala de aula. 
No artigo $6^{\circ}$ da Lei federal 12.319 de 2010 , em seu inciso $3^{\circ}$ aponta que cabe ao profissional: interpretar, em Língua Brasileira de Sinais - Língua Portuguesa, as atividades didático-pedagógicas e culturais desenvolvidas nas instituições de ensino nos níveis fundamental, médio e superior, de forma a viabilizar o acesso aos conteúdos curriculares (BRASIL, 2010).

Entretanto, para que o aprendizado do aluno surdo aconteça, é preciso um contexto inclusivo, onde professor, intérprete e o próprio aluno surdo estejam atuando em sincronia. O professor e o intérprete precisam trabalhar em conjunto, essa é uma das estratégias de aprendizagem apresentada por Urban et al. (2016), a ação conjunta do TILS e professor, trocando informações sobre o aprendizado do aluno surdo, para que ele não seja prejudicado e a inclusão aconteça.

Nesse sentido, acredita-se que o trabalho conjunto entre o professor e o tradutor intérprete de Língua de Sinais são fundamentais para potencializar os processos de ensino e aprendizagem e também contribuir para a inclusão e permanência desse aluno no contexto acadêmico.

A indissociabilidade do trabalho desses profissionais é imprescindível na criação de estratégias didático-pedagógicas para contemplar as especificidades da comunidade surda e integrá-los no desenvolvimento da prática docente, tornando o aluno o protagonista de seu próprio saber e agente de transformação da sua realidade, ao contrário de práticas tradicionais que mascaram a inclusão e promovem uma "pseudointegração" do aluno surdo nas atividades universitárias. Desse modo, o professor em conjunto com o TILS pode reinventar suas performances educativas e o aluno surdo de um mero receptor de conhecimento e ser adaptável passa a promover a construção do conhecimento e participar efetivamente do processo pedagógico.

A inclusão no contexto do Ensino Superior não é um caminho fácil pois os alunos entram em contato com ambientes onde o português é a língua predominante, a organização e as demandas para os estudos são densas, além da produção seja de artigos, ensaios, provas, são rotinas constantes no ambiente universitário em que esses acadêmicos precisam dar conta, estes e outros fatores influenciam na trajetória acadêmica do aluno, onde muitos acabam desistindo pelo baixo rendimento.

A lei que oficializa a Libras (BRASIL, 2002) mostra que a Língua Brasileira de Sinais não poderá substituir a modalidade escrita da língua portuguesa, ou seja há a necessidade da escrita e a leitura do português por parte dos surdos nas instituições de Ensino Superior e talvez essa seja uma das barreiras na aprendizagem deles. Neste 
sentido, as metodologias em sala de aula devem compreender este universo de defasagem e propiciar ao mesmo tempo uma intervenção para que os componentes curriculares sejam compreendidos por tais acadêmicos.

De acordo com Urban et al (2016), a escola, em geral, está presa ao texto didático como caminho único para a apresentação de conceitos, e este caminho tem se mostrado pouco produtivo quando se pensa na presença de alunos surdos em sala de aula. Este princípio também pode ser evidenciado no contexto da universidade, sendo que outros recursos podem ser imprescindíveis para o aprendizado do aluno surdo. Então nesse caso, outra estratégia de aprendizagem pode ser considerada como o texto didático.

Nessa direção, Urban et al (2016) aborda que o professor envolvido com a educação inclusiva deve estar preparado para atuar nessa realidade, repensando suas práticas tradicionais utilizadas com alunos ouvintes e fazendo a transposição para o trabalho com alunos surdos. Torna-se relevante este preparo, pois esse aluno precisará de um material de apoio diferenciado com ilustrações, tendo em vista a dificuldade na leitura de textos longos para leitura e interpretação, sabendo que os surdos possuem as habilidades visuais bem mais desenvolvidas que os ouvintes.

Stolz et al (2019), apresentou uma ação que acompanha o desempenho de alunos surdos, no decorrer do curso, a partir de suas demandas e de acordo com a sua deficiência, consiste é uma estratégia para favorecer a aprendizagem. Docentes do curso que o estudante surdo frequenta são contatados, para pensar em diferentes estratégias para o alcance dos objetivos. Desse modo, o acompanhamento com identificação de necessidades específicas de aprendizagem, passa a ser uma estratégia de aprendizagem. Os acadêmicos surdos juntamente com a Coordenadoria de Ações Educacionais - CAED e a equipe de Tradutores Intérpretes de Libras organizam o acolhimento aos calouros surdos que são recebidos por acadêmicos veteranos e formados pela UFSM.

Outra estratégia de aprendizagem, extraída do estudo de Stolz (2019), trata-se de um momento de acolhimento. São falas de acadêmicos já egressos, onde os próprios surdos orientam os recém estudantes ingressos, sobre o que é o ambiente acadêmico, o papel do aluno no contexto da universidade, o papel do Intérprete de Libras.

A oferta do Atendimento Educacional Especializado (AEE) mostra ser uma estratégia adequada para esses estudantes. Lima (2018) e Stolz (2019), mencionam a existência de um serviço com psicólogos, psicopedagogos e educadores especiais realizando o suporte para que as demandas dos acadêmicos sejam sanadas. Por meio dos serviços desses profissionais, que se constituem como uma equipe, em sala de aula os 
docentes são orientados a disponibilizar o material com antecedência para os TILS, o que vem a ser um ótimo recurso para a aprendizagem, pois além da previsão daquilo que o estudante vai aprender, há um suporte para que essa aprendizagem ocorra com mais elementos que tendem a favorecer os componentes a serem aprendidos. Ainda por meio dessa mesma equipe, no contra turno há o atendimento por bolsistas que trabalham com as demandas específicas dos componentes curriculares.

Além disso, Urban et al (2016) propõe que para ocorrer o aprendizado do aluno surdo é preciso estar presente quatro protagonistas: profissionais da educação (pedagogo), professor, intérprete e o próprio aluno, mas, infelizmente, na prática isso não ocorre e as metodologias aplicadas em sala de aula permanecem as mesmas, tanto para ouvintes quanto para surdos. Os professores precisam abordar os seus conteúdos de uma forma visual, pois a alfabetização surda acontece nesse contexto, então, o uso de imagens facilita o desenvolvimento da competência linguística e contribui para minimizar lacunas no aprendizado desse aluno.

Goularte (2014), dirigindo o foco do estudo para o ingresso e a permanência, buscou compreender as estratégias de governamento da conduta de alunos surdos incluídos no contexto da UFSM. O discurso de benevolência opera nos processos de ensino e aprendizagem, visto que são oferecidas proteção e vantagens ao aluno surdo para que ele permaneça na universidade, como por exemplo: não reprová-lo por falta e mal desempenho na avaliação, compreender suas ausências ou atrasos nas aulas, ou seja, situações nas quais os professores querem se desresponsabilizar pela reprovação do aluno em virtude de uma proteção, onde há a persistência de práticas assistencialistas que menosprezam as capacidades individuais de cada um.

Nesse sentido, uma estratégia, extraída a partir da interpretação desse estudo, seria a de reconhecimento do potencial de aprendizagem do surdo. Desenvolver práticas no contexto acadêmico, com esse entendimento. Goularte (2014) referiu que o aluno surdo se torna invisível durante sua inserção acadêmica, pois o professor planeja as aulas considerando os alunos ouvintes, desconsiderando os alunos surdos. $\mathrm{O}$ aluno surdo não se coloca como protagonista de sua aprendizagem e acaba esperando pela atitude dos professores ou colegas para realizar as atividades acadêmicas; em outras, mostra-se despreocupado com o aprendizado dos conteúdos e descompromete-se com sua vida estudantil, pois o que realmente importa é o status de estar matriculado em uma universidade pública e gratuita. 
Com o acesso há investimentos no aspecto linguístico e cultural do surdo, pois eles têm acesso ao edital e vestibular em Libras, a correção da redação de forma diferenciada e ao projeto de extensão, entre outros; porém, no ingresso há estratégias de governamento para permanência, no qual o aluno surdo é exaltado, tutelado e torna-se invisível para permanecer; entretanto, não há o mesmo investimento em Libras durante a permanência, ou seja, essa Língua não funciona como um marcador da diferença cultural e linguística do surdo e para manter-se na instituição, o referido aluno elabora variadas estratégias (GOULARTE, 2014).

Lima (2018) buscou entender de que forma as estratégias de ensino utilizadas pelos professores contribuem para a aprendizagem de acadêmicos surdos, considerando que cada professor tem uma maneira de ensinar e os alunos apresentam estilos de aprendizagem individuais. O interesse dos professores em aprofundar seus conhecimentos a respeito da comunidade surda, reconhecendo as diferenças individuais, motivando os alunos a permanecerem no curso, enfatizando a importância da aplicabilidade dos conteúdos em suas trajetórias profissionais, estimulando e criando situações de aprendizagem, são essenciais à permanência. Diante disso, a estratégia em que reconhecidamente a formação continuada seja incentivada no ambiente acadêmico é fundamental para os processos de inclusão.

Ser professor é complexo, pois os alunos demandam aulas inovadoras, no entanto, as estratégias de ensino utilizadas pelos docentes não são suficientes para que os alunos surdos tenham condições de acompanhar os conteúdos, tendo em vista que o foco da aprendizagem dos surdos limita-se somente as habilidades cognitivas e não com o objetivo à garantia da permanência e da conclusão dos estudos dos acadêmicos surdos que ingressam na Educação Superior. Todas essas ações visam atender o acadêmico de forma integral, permitindo que supere suas defasagens e consigam a diplomação.

\section{Conclusão}

A inclusão de alunos surdos no Ensino Superior é uma realidade que é repensada para além do processo de ingresso, olhar para as concepções de ensino as quais as pessoas surdas foram atreladas, se torna necessário para entender os processos contextuais históricos dessas pessoas, pois suas potencialidades e dificuldades em contato com a dinâmica do Ensino Superior podem ser desconhecidas e por isso incompreendidas.

As condições de acesso, às pessoas com deficiência, foram regularizadas pela garantia legal, da mesma forma a presença de TILS. Entretanto, são direitos que não 
garantem a aprendizagem, e a língua portuguesa, é ainda a maior barreira para a aprendizagem. Isso considerando que a Língua de Sinais não é substitutiva do português.

Desse modo, tendo presente o objetivo desse estudos que consistiu em compreender o fomento metodológico de permanência no Ensino Superior, em especial das estratégias de ensino utilizadas, conclui-se que as estratégias de aprendizagem para estudante surdos, indicam ser mais efetivas para o alcance dos objetivos acadêmicos quando são conhecidas pelas partes (professor, aluno e TILS), pois o uso de apenas uma das estratégias identificadas no estudo, pode ser ineficaz para o alcance dos objetivos acadêmicos.

A contribuição que essa pesquisa traz à tona, entendendo ser mais um passo no caminho da inclusão, é a de que as estratégias de ensino e aprendizagem que podem colaborar com a aprendizagem do surdo, podem não ser ampla e profundamente exploradas pelos atores do processo pedagógico. Embora conhecidas, podem não ser efetivamente utilizadas em sua capacidade total.

Além das estratégias apresentadas nesse estudo: ação conjunta do TILS, texto didático, momento de acolhimento, acompanhamento com identificação de necessidades específicas de aprendizagem, Atendimento Educacional Especializado-AEE, reconhecimento do potencial de aprendizagem, formação continuada - outras podem ser desenvolvidas a partir da realidade de cada estudantes, professor e contexto acadêmico, o que amplia as possibilidades de pesquisa nessa área.

O estudo, como se espera, apresenta limitações, isso dito pelo fato de apresentar uma única realidade institucional, o que aponta para a possibilidade de ser ampliado para outros cenários universitários, das próprias IES públicas, ou ainda, das instituições privadas de Ensino Superior que são em maior número no Brasil e que podem ter outras estratégias de aprendizagem.

\section{Referências}

ALMEIDA, Laisa de Castro. Trajetórias escolares de estudantes surdos e seus efeitos nos processos inclusivos no ensino superior. Dissertação. (Mestrado em Educação), Universidade Federal de Santa Maria, Santa Maria-RS, Brasil, 2018.

BRASIL. Lei n. 9.394, de 20 de dezembro de 1996. Estabelece as diretrizes e bases da educação nacional. Diário Oficial da República Federativa do Brasil. Brasília, DF, 23 dez. 1996. Disponível em: http://www.planalto.gov.br/ccivil_03/leis/19394.htm. Acesso em: 2 maio 2020. 
BRASIL. Ministério da Educação. Aviso Circularn n 277, de 08 de maio de 1996. BrasíliaDF, 1996. Disponível em: portal.mec.gov.br/seesp/arquivos/pdf/aviso277.pdf Acesso em: 10 nov. 2019.

BRASIL. Ministério da Educação. Portaria no 1.679, de 2 de dezembro de 1999. Dispõe sobre requisitos de acessibilidade de pessoas portadoras de deficiências, para instruir os processos de autorização e de reconhecimento de cursos, e de credenciamento de instituições. Disponível em: http://portal.mec.gov.br/sesu/arquivos/pdf/c1_1679.pdf. Acesso em: 30 mar. 2020.

BRASIL. Educação para todos: avaliação da década. Brasília: MEC/INEP, 2000.

BRASIL. Ministério da Educação. Secretaria de Educação Especial. Diretrizes Nacionais para a Educação Especial na Educação Básica. Brasília: MEC; SEESP, 2001. Disponível em: http://portal.mec.gov.br/seesp/arquivos/pdf/diretrizes.pdf. Acesso em: 4 jun. 2020.

BRASIL. Lei no 10.436, de 24 de abril de 2002. Dispõe sobre a Língua Brasileira de Sinais e dá outras providências. Diário Oficial da União, Brasília, 25 de abril de 2002.

BRASIL. Ministério da Educação. Secretaria de Educação Especial. Política Nacional de Educação Especial na Perspectiva da Educação Inclusiva. Brasília: 2008. Disponível em:

http://portal.mec.gov.br/arquivos/pdf/politicaeducespecial.pdf. Acesso em: 2 maio 2020.

BRASIL. MEC/SEESP. Presidência da República. Decreto nº 6.571, de 17 de março de 2008a. Dispõe sobre o atendimento educacional especializado, regulamenta o parágrafo único do art.60 da Lei n. 9.394, de 20 de dezembro de 1996, e acrescenta dispositivo ao Decreto n. 6.253, de 13 de novembro de 2007. Diário Oficial da União, Brasília, nº 188, 18 de setembro de 2008.

BRASIL. Lei $\mathrm{n}^{\mathrm{o}} 12.319$, de $1^{\circ}$ de setembro de 2010. Regulamenta a Profissão de Tradutor e Intérprete da Língua Brasileira de Sinais. Disponível em: www.planalto.gov.br/ccivil_03/_Ato2007-2010/2010/Lei/L12319.htm Acesso em: 10 nov. 2019.

BRASIL. Lei $\mathrm{n}^{\circ}$ 13.711/2012, de 29 de Agosto de 2012. Dispõe sobre o ingresso nas universidades federais e nas instituições federais de ensino técnico de nível médio e dá outras providências. Disponível em: http://www.planalto.gov.br/ccivil_03/_ato20112014/2012/lei/112711.htm. Acesso em: 19 nov. 2019.

BRASIL. Ministério da Educação. Planejando a Próxima Década. Conhecendo as 20 Metas do Plano Nacional de Educação. Ministério da Educação/Secretaria de Articulação com os Sistemas de Ensino (MEC/Sase): Brasília, DF., 2014.

BRASIL. Ministério da Educação. Instituto Nacional de Estudos e Pesquisas Educacionais (Inep). Sinopse Estatística da Educação Superior 2017. [on line]. Brasília: Inep, 2017. Disponível em: http://portal.inep.gov.br/basica-censo-escolar-sinopsesinopse. Acesso em: 28 dez. 2019. 
BISOL, Cláudia Alquati et al. Estudantes surdos no ensino superior: reflexões sobre a inclusão. Cafajeste. Pesqui. São Paulo, v. 40, n. 139, p. 147-172, abril de 2010. Disponível em: http://www.scielo.br/scielo.php?script=sci_arttext\&pid=S010015742010000100008\&lng=en\&nrm=iso. Acesso em: 4 jun. 2020. http://dx.doi.org/10.1590/S0100-15742010000100008.

CAETANO, Fonseca Juliana; LACERDA, Cristina; SANTOS Lara. Estratégias metodológicas para o ensino de alunos surdos. Disponível em: http://ufscarlibras.blogspot.com/ Acesso em: 18 nov. 2019.

CORCINE, Lopes Maura. Surdez e educação. Belo Horizonte: Autêntica, 2007.

DAROQUE Samantha Camargo; PADILHA Anna Maria Lunardi. Alunos surdos no Ensino Superior: uma discussão necessária. Comunicações. Piracicaba Ano 19, n. 2, p. 23-32 jul.-dez. 2012. Disponível em:https://www.metodista.br/revistas/revistasunimep/index.php/comunicacoes/article/view/1534/1088 Acesso em: 27 dez. 2019.

FERREIRA Aline do Prado; CEZAR Amanda do Prado Ferreira. A promoção da Aprendizagem da Língua Portuguesa para estudantes surdos no Ensino Superior. In: PAVÃO, Ana Claudia Oliveira; PAVÃO, Silvia Maria de Oliveira. Atendimento Educacional Especializado: reflexões e práticas necessárias para a inclusão. Santa Maria: Ed. pE. Com. UFSM, 2018, p. 354.

GIL, A. C. Métodos e técnicas da pesquisa social. 5. ed. São Paulo: Atlas, 2008.

GÓES, M.C.R. Com quem as crianças dialogam? In: GÓES, M.C.R.; LACERDA, C.B.F. (orgs.). Surdez: processos educativos e subjetividade. São Paulo: Lovise, 1999. p. 29-50.

GOULARTE, Ravele Bueno. Acesso e permanência no ensino superior: estratégias de governamento da conduta de alunos surdos incluídos. Dissertação. (Mestrado em Educação), Universidade Federal de Santa Maria, Santa Maria-RS, Brasil, 2014.

INSTITUTO NACIONAL DE ESTUDOS E PESQUISAS EDUCACIONAIS ANÍSIO TEIXEIRA (INEP). Censo da Educação Superior, 2017. Brasília: MEC, 2017.

LACERDA, C. B. F; SANTOS, L.F. Tenho um aluno surdo. E agora? Introdução à Libras e educação de surdos. São Carlos: EdUFScar, 2014.

LAVARDA, Eliane Sperandei. O currículo e a inclusão na educação superior: ações de permanência nos cursos de graduação da UFSM. Dissertação. (Mestrado em Educação), Universidade Federal de Santa Maria, Santa Maria-RS, Brasil, 2014.

LIMA, Juliana Corrêa de. Estratégias para acadêmicos surdos na educação superior. Dissertação. (Mestrado em Educação), Universidade Federal de Santa Maria, Santa Maria-RS, Brasil, 2018.

MENDES, K.D.S.; SILVEIRA, R.C.C.P.; GALVÃO, C.M. Revisão integrativa: método de pesquisa para incorporação de evidências na saúde e na enfermagem. Revista Texto e Contexto-Enfermagem, 17(4), 758-764. doi: 10.1590/S0104-07072008000400018. 
PELLEGRINI, Cleonice Machado de. Ingresso, acesso e permanência de alunos com necessidades educacionais especiais na Universidade Federal de Santa Maria - UFSM - RS. Dissertação. (Mestrado em Educação), Universidade Federal de Santa Maria, Santa Maria-RS, Brasil, 2006.

PERLIN, Gladis; STROBEL, Karin Lílian. Fundamentos da Educação de Surdos. Florianópolis: UFSC, 2006.

SANTANA, Ana Paula. A Inclusão do Surdo no Ensino Superior no Brasil. Journal of Research in Special Educational Needs. v. 16, n. 1, 2016. Disponível em: Santana-2016Journal_of_Research_in_Special_Educational_Needs.pdf. Acesso em: 12 nov. 2019.

SOUZA, M. T.; SILVA, M. D.; CARVALHO, R. (2010). Revisão integrativa: o que é e como fazer. Einstein, 8(1), 102-6. ISSN: 2317-6385.

STOLZ, Mariléia Lúcia Stolz. Vivência acadêmica de estudantes surdos na UFSM: ingresso, adaptação, permanência e conclusão. Dissertação. (Mestrado em Psicologia), Universidade Federal de Santa Maria, Santa Maria-RS, Brasil, 2019.

STOLZ, Mariléia Lúcia et al. Acessibilidade dos surdos no Ensino Superior: realidade da UFSM. In: ADAIME, Martha Bohrer et al. Promoção da Aprendizagem e Tecnologias Educacionais: Aprendizagem no Ensino Superior Acessibilidade e Ações Afirmativas. Santa Maria, RS: FACOS-UFSM, 2019. e-book.

STUMPF, Marianne Rossi. Práticas de Bilinguismo relato de experiências. Educação Temática Digital, Campinas, v.7, n.2, p. 285-91, 2006.

UECKER, Taciana; BUENO, Évelyn da Rocha; FIORIN, Bruna Pereira Alves. Prevenção e Promoção da aprendizagem e saúde na Educação Superior. In: PAVÃO, Ana Claudia Oliveira; PAVÃO, Silvia Maria de Oliveira. Atendimento Educacional Especializado: Aprendizagem Saúde e Inclusão. Santa Maria: Ed. pE. Com. UFSM, 2018.

UNIVERSIDADE FEDERAL DE SANTA MARIA, 2020. Manancial- Repositório Digital. Disponível em: https://repositorio.ufsm.br/ Acesso em: 2 maio 2020.

URBAN, Retko Juliane et al. O aluno surdo e o processo de aprendizagem na educação profissional. In: Simpósio Nacional de Ensino de Ciência e Tecnologia, 2016. Disponível em: http://www.sinect.com.br/2016/down.php?id=3472\&q=1 Acesso em: 09 nov. 2019.

WITCHS, Pedro Henrique; LOPES, Maura Corcini; COELHO, Orquídea. Formas possíveis de ser nas políticas linguísticas de educação de surdos em Portugal. Educ. Soc., Campinas, v. 40, 2019.

UNESCO. Declaração Mundial sobre Educação para Todos: satisfação das necessidades básicas de aprendizagem, Jomtien, Tailândia 1990. Disponível em: http://unesdoc.unesco.org/images/0008/000862/086291por.pdf. Acesso em: 2 maio 2020.

Artigo recebido em 09 de junho de 2020. Aprovado em 09 de março de 2021. 